\title{
ВЛИЯНИЕ ЦЕЛЕЙ ТЫСЯЧЕЛЕТИЯ ООН НА СНИЖЕНИЕ РИСКА БЕДСТВИЙ В КОНТЕКСТЕ УСТОЙЧИВОГО РАЗВИТИЯ
}

\section{THE IMPACT OF THE UN MILLENNIUM GOALS ON DISASTER RISK REDUCTION IN THE CONTEXT OF SUSTAINABLE DEVELOPMENT}

\section{Plyushchikov}

Summary: The purpose of the article is to analyze the UN Millennium Goals, as a principles of sustainable development and the search for the initial prerequisites for the establishment of international cooperation in the field of disaster risk reduction. Special research methods of international relations, such as the method of instrumental observation, the method of studying documents, as well as a systematic approach, which made it possible to trace the prerequisites for the establishment of a system of international cooperation in the field of disaster risk reduction. The study showed that the Millennium Declaration adopted by UN member countries does not have specific provisions related to disaster risk reduction, even in countries with high risk of this issue. The Millennium Development Goals are aimed at other areas of interaction between the UN member countries. There are separate provisions that do not contradict and form the prerequisites for creating a unified concept of disaster risk reduction in the Millennium Development Goals, as enshrined in the Millennium Declaration.

Keywords: Millennium Declaration, Millennium Development Goals, sustainable development, international cooperation, disaster risk reduction.

\author{
Плющиков Владислав Вадимович \\ аспирант, Российский Университет Дружбы Народов \\ pliushchikov_vv@rudn.university.ru
}

Аннотация: Цель статьи заключается в анализе Целей Тысячелетия 00H, которые в своей основе составили принципы устойчивого развития и поиске первоначальных предпосылок к становлению международного сотрудничества в области снижения риска бедствий. Специальные методы исследования международных отношений, такие как метод инструментального наблюдения, метод изучения документов, а также системный подход, что позволило отследить предпосылки становления системы международного сотрудничества в области снижения риска бедствий. Проведенное исследование показало, что принятая странами-членами 00Н Декларации Тысячелетия не имеет конкретных положений, связанных со снижением риска бедствий, в частности, в странах с высоким риском данной проблематики. Цели Развития Тысячелетия направлены на другие отрасли взаимодействия стран-членов 00Н. На основе данного исследования делается вывод, что в Целях Развития Тысячелетия, закрепленных в Декларации Тысячелетия, существуют отдельные положения, которые не противоречат и формируют предпосылки к созданию единой концепции снижения риска бедствий.

Ключевые слова: Декларация Тысячелетия, Цели Развития Тысячелетия, устойчивое развитие, международное сотрудничество, снижение риска бедствий.

на свободном, равном электоральном участии всего населения. Кроме того, в Декларации были закреплены принципы социального, политического и гендерного равенства, солидарности, социальной справедливости в решении глобальных проблем. Эти вопросы, относимые в большей степени к сфере гуманитарного права и прав человека, уже, применительно к Декларации и промежуточным итогам её выполнения, широко освещены в российской литературе. [2]

Декларация, как это ни странно, отдельно не затронула вопросы стихийных бедствий, которые, находясь вне политики и геополитики, продолжают угрожать жизни людей и инфраструктуре, являясь глобальной угрозой, которой предстоит противостоять в наступившем тысячелетии.

В то же время, международные организации признают, что стихийные бедствия угрожают обесценить достижения в области развития и препятствуют достижению 
Цели развития тысячелетия. Так, Международная федерация Красного Креста и Красного Полумесяца исходит из того, что бедствия являются не просто гуманитарной проблемой, а и проблемой развития. Организация видит все больше доказательств того, что страны с низким развитие человеческого потенциала терпят несоразмерные убытки от воздействия стихийных бедствий, люди по-прежнему уязвимы к опасностям из-за отставания в социально-экономическом развитии.[3] В этом смысле Декларация особенно актуальна, хотя и не содержит положений, прямо указывающих на стихийные бедствия.

$\mathrm{OOH}$ признает учащение стихийных бедствий во всем мире в целом, а особенно - в Азии и Тихоокеанском регионе. Их подверженность риску растет по мере увеличения темпов урбанизации, а соответственно и концентрации населения, а также экономики в районах, как правило, прибрежных.[4] По данным специалистов Технологического института Карлсруэ (Германия), обобщившим глобальные сведения о 35 тысячах стихийных бедствий за 1900-2015 годы, совокупный ущерб человечеству за указанный период составил \$7 трлн., погибли свыше 8 млн. человек. При этом до 40\% экономического ущерба причинили наводнения, до 25\% - землетрясения, до $20 \%$ - штормы, около 12\% - засухи, около 2\% - лесные пожары и менее чем 1\% - вулканическая деятельность. Все эти явления, в наступившем тысячелетии продолжают угрожать человечеству. По данным указанного анализа в абсолютном выражении убытки в исследованном интервале демонстрировали рост. В то же время, сегодня они составляют меньший процент от общей стоимости уничтоженной и поврежденной инфраструктуры. Отсюда вывод о том, что человечество более эффективно противостоит стихии, хотя и видны явные страновые и региональные различия.[5]

На момент принятия Декларации международное сообщество ещё не выработало общего определения понятия «бедствие». Сегодня оно трактуется как ситуация (событие), выходящее за рамки местных возможностей, требующее оказания внешней помощи на национальном либо международном уровне в силу непредвиденного и внезапного разрушительного стихийного воздействия, повлекшего большой ущерб, разрушения, гибель и страдания людей. Данное определение используется Исследовательским центром по проблемам эпидемиологии бедствий (ИЦЭБ) ВОЗ. Этот Центр накапливает глобальную базу данных о бедствиях.

Международный мониторинг экологических, социальных и экономических последствий бедствий важен для разработки международных программ прогнозирования, помощи и принятия экстренных решений по всей совокупности вопросов, реагирования на чрезвычайные происшествия.
Принято считать, что наиболее разрушительные природные бедствия: штормы, тайфуны, цунами и наводнения порождают сегодня две трети всех природных чрезвычайных ситуаций. Оставшаяся треть - это, в основном землетрясения и засуха. Статистика убедительно показывает, что большая часть этих явлений приходится на страны Азии и Африки. 95\% человеческих жертв от различных стихийных бедствий и природных катастроф приходится на бедные и развивающиеся страны. Их убытки до 20 раз превышают убытки развитых стран. Кроме того, бедствия, вызывают эпидемии уже известных и новых (мутационных) инфекционных болезней.[6] В то же время, нельзя считать, что проблема стихийных бедствий в новом тысячелетии - это вопрос только бедных и развивающихся стран.

Из развитых стран со стихийными бедствиями встречаются, прежде всего, США. Ущерб от них колоссален. Достигнув в 2017 г. исторического максимума, он, по данным Национального управления океанических и атмосферных исследований США,[7] составил \$306 млрд. В 2015 г. ущерб достигал \$215 млрд. Один ураган способен причинить колоссальный ущерб. Так, только ураган «Харви» стоил экономике США \$125 млрд.; урагана «Мария» \$90 млрд., урагана «Ирма» - \$50 млрд. Кроме того, в Техасе, Луизиане и других южных штатах, нередки катастрофические лесные пожары, убыток от которых (в целом по США) в 2017 г. достиг \$18 млрд., что сразу в три раза превысило ранее действовавший показатель. В 2017 г. в результате 16 крупных стихийных бедствий в США погибли 362 человека.[8]

Декларация не содержит положений о глобальном противодействии стихийным бедствиям, соединении усилий в деле минимизации ущерба. Проблема международного взаимодействия в данной сфере, в том числе и в том, что на национальном уровне такого рода вопросы не всегда разработаны. Так, в США лишь в 2017 г., после катастрофического ущерба и после 40 лет разрозненных действий различных служб, была запущена Программа готовности к стихийным бедствиям (The OR\&R Disaster Preparedness Program (DPP) Управления реагирования и восстановления (OR\&R), направленная на обеспечение по-настоящему эффективного состояния готовности, основанной на постоянной бдительности и постоянных улучшениях. Программа OR\&R по обеспечению готовности к стихийным бедствиям (DPP) была запущена в 2017 г. для подготовки Национальной океанской службы (NOS), а также её партнеров к реагированию и восстановлению после масштабных загрязнений и стихийных бедствий. В данном случае, опираясь на деятельность Центра реагирования на стихийные бедствия в Мексиканском заливе (DPC), DPP использует и укрепляет существующие оперативные возможности и знания для обеспечения того, чтобы торговля, и природные ресурсы как можно быстрее восстанавливались после стихийных бедствий. 
План DPP включает обучение, тренировки, извлечение уроков из опыта. Основная работа проводится в рамках NOAA по экстренному реагированию на стихийные бедствия по всей стране, чтобы обеспечить быстрый ответ угрозам, в основном для прибрежных районов.

Во время стихийных бедствий или техногенных катастроф DPP координирует работу для партнеров по NOS, которые выполняют критически важные задачи по предоставлению информации о разливах нефти, иных химических веществ, оценке ущерба окружающей среде и инфраструктуре, планированию сохранения и восстановления среды обитания и т.п.

В то же время, ни DPC, ни DPP, ни NOAA почти ничего не говорят о сотрудничестве со странами - соседями, прежде всего, Мексикой. Американский (как и российский) опыт может быть ценен в международном плане, в том числе в целях Декларации, если бы в ней были поставлены соответствующие вопросы.

В то же время, Декларация в большей степени ориентирована на построение в наступившем тысячелетии справедливого, демократического мира, такого который предусматривался в основополагающих документах по правам человека, принятым в послевоенный период.

Применительно к последствиям бедствий и катастроф, положения Декларации, могут быть поняты как то, что бремя тяжелых издержек не должно будет ложиться исключительно на пострадавших и нуждающих- ся в помощи. В соответствии с Декларацией, они должны быть поддержаны и защищены теми, кто находится в более благоприятном положении и способен такую помощь оказать. В Целях и Задачах Декларации Тысячелетия ООН возможно отследить косвенные предпосылки, которые не противоречат принципам снижения риска бедствий, а некоторые можно рассмотреть, как основу становления международного сотрудничества. Задача по сокращению голода имеет прямую связь со снижением риска бедствий, так как не противоречит определению термина «бедствие», принятого ООН и используемого ВОЗ. Сокращение детской и материнской смертности, борьба с распространением заболеваний и инфекций, обеспечение экологической устойчивости, сохранение биологического разнообразия, формирование единого партнерства в области развития - все эти Цели и Задачи были впоследствии уточнены и легли в основу и становление единой программы снижения риска бедствий (Хиогскую рамочную программу снижения риска бедствий, и следующую за ней Сендайскую рамочную программу). [9]

Также, из Декларации может быть использован принцип общей обязанности, распространяемый как на управление глобальным экономическим и социальным развитием, так и на предотвращение или минимизацию ущерба от глобальных угроз. Такая обязанность, исходя из Декларации, считается общей для всех государств и народов и пропорционально делится. Координирующую роль здесь играет $\mathrm{OOH}$, как специально созданная представительная и универсальная организация.[10]

\section{ЛИТЕРАТУРА}

1. Декларация тысячелетия Организации Объединенных Наций// Un.org: Организация Объединенных Наций (00H).http://www.un.org/ru/documents/ decl_conv/declarations/summitdecl.shtml

2. Юсупов Р.М. Декларация тысячелетия 00Н и общечеловеческие ценности// Современное право. 2016. № 11. С. 122-125;

3. The Hyogo Framework for Action and the International Federation/ URL: https://www.ifrc.org/Global/hyogo-framework-federation-en.pdf

4. Углубленный анализ темы измерения экстремальных явлений и бедствий Национального института статистики и географии (ИНЕГИ) Мексики// Организация Объединенных Наций ECE/CES/2015/9 https://www.unece.org/fileadmin/DAM/stats/documents/ece/ces/2015/9-Rus_In_depth_review_of_ measuring_disasters.pdf

5. Ученые подсчитали ущерб от стихии в мире за 115 лет// ВBC. Русская служба. 2016. 19 апреля. URL: https://www.bbc.com/russian/ science/2016/04/160419_natural_disasters_economic_losses

6. Аль Сабунчи А.А. Последствия природных катастроф в развивающихся странах// Вестник Российского государственного медицинского университета. 2009. № 5. C. 92-94.

7. National Oceanic and Atmospheric Administration (NOAA). Как это ни странно, но в (ША сумму ущерба экономике определяет именно метеорологическое ведомство/ https://www.noaa.gov

8. Ведомости. 2018. 9 января URL: https://www.vedomosti.ru/economics/news/2018/01/09/747231-uscherb-ot-stihiinih-bedstvii-ssha

9. Ц Цели развития тысячелетия https://www.un.org/development/desa/ru/millennium-development-goals.html

10. Ведомости. 2018. 9 января URL: https://www.vedomosti.ru/economics/news/2018/01/09/747231-uscherb-ot-stihiinih-bedstvii-ssha

(с Плющиков Владислав Вадимович (pliushchikov_vv@rudn.university.ru).

Журнал «Современная наука: актуальные проблемы теории и практики» 